Case Reports
in Dermatology
Case Rep Dermatol 2021;13:54-57

DOI: 10.1159/000511998

Published online: January 28, 2021 (c) 2021 The Author(s)

Published by S. Karger AG, Basel www.karger.com/cde

\title{
Spontaneous Regression of Palmar Warts after Suffering from Diffuse Contact Dermatitis against Alkyl Bromide
}

\author{
Gyohei Egawa Tetsuya Honda Kenji Kabashima \\ Department of Dermatology, Kyoto University Graduate School of Medicine, Kyoto, Japan
}

\section{Keywords}

Verruca vulgaris $\cdot$ Spontaneous regression $\cdot$ Hapten

\begin{abstract}
Contact immunotherapy with several sensitizing chemicals such as diphenylcyclopropenone (DPCP) or squaric acid dibutyl ester (SADBE) have been used for the treatment of recalcitrant or multiple warts. Here, we report a case of multiple verrucae vulgaris (VV) on the palm which spontaneously resolved after the development of systemic contact dermatitis against alkyl bromide. We considered that our case accidentally mimics contact immunotherapy against multiple VV. VV sometimes regress spontaneously, which may be triggered by accidental contact dermatitis, as shown in our case.

(C) 2021 The Author(s)

Published by S. Karger AG, Basel
\end{abstract}

\section{Introduction}

Verruca vulgaris (VV) is a common skin disease caused by human papilloma virus (HPV) infection. Contact immunotherapy with several sensitizing chemicals, such as diphenylcyclopropenone (DPCP) or squaric acid dibutyl ester (SADBE), has been used for the treatment of recalcitrant or multiple warts. Here, we report a case of multiple VV on the palm that spontaneously resolved after suffering from diffuse contact dermatitis against alkyl bromide. 


\section{Case Reports in Dermatology}

\section{Case Presentation}

A 25-year-old Japanese man visited our clinic complaining of rashes on the right thigh. He had been engaged in chemical experiments, and 12 days before the visit (hereafter referred to as day 0 ), he had spilt alkyl bromide on his right thigh. On day 1-2, erythema with tiny vesicles had appeared on the thigh, and on around day 7, he had complained of fever and vomiting, and the erythema had spread over the trunk. He had visited a dermatologist nearby and then had been referred to our clinic (on day 12).

He presented uncircumscribed erythema on his right thigh (Fig. 1a). The erythema on the trunk had disappeared by this time. At the same time, we noticed that several warts on his left palm, which he had suffered from for years in spite of multiple cryotherapies, had turned brownish (Fig. 1b, c). Histological analysis of the right thigh revealed massive infiltration of lymphocytes and vacuolar changes of the epidermis (Fig. 1d, e). Based on these clinical and histological observations, we diagnosed him with contact dermatitis with systemic symptoms and prescribed a topical steroid (clobetasol propionate) ointment. The rashes on the thighs had disappeared by the visit on day 21, and by his next visit on day 50, all the VV on the palm had resolved (Fig. 1f). Based on this clinical course, we considered that the VV on his palm had spontaneously regressed due to an immunological mechanism.

\section{Discussion and Conclusion}

Since alkyl bromide contains a halogen, it could act as a hapten, a strong sensitizer, when the human body is exposed to it [1]. In our case, the patient was exposed to alkyl bromide over a wide area of the thighs $\left(>500 \mathrm{~cm}^{2}\right)$; thus, cellular immunity must have been strongly activated in his body. Indeed, the patient presented systemic symptoms and the erythema transiently spread over unexposed sites such as the trunk. This systemic activation of cellular immunity must have served as an eliminator of VV on the whole body.

We could not clarify whether the patient had been naive or presensitized against alkyl bromide on the day of broad exposure to this hapten (day 0); previous reports have shown that single exposure to a hapten (i.e., irritant contact dermatitis) could be sufficient to develop systemic immunity against warts [2]. A similar phenomenon was also described with verruca plana [3] and molluscum contagiosum [4], although the precise mechanism is left unclarified.

Although the patient was uncertain whether the alkyl bromide had directly touched the VV on his left palm or not, both an antigen-specific and a nonspecific mechanism may have been involved. If alkyl bromide directly bonds to HPV-infected keratinocytes, VV must be attacked by alkyl bromide-specific CD8+ cytotoxic T cells; even if this is not the case, antigennonspecific immunity can be induced during contact immunotherapy. Previous studies have reported regression of warts at untreated sites during immunotherapy [3], suggesting that direct hapten binding is not necessary to eliminate HPV-infected keratinocytes.

In conclusion, our case accidentally mimicked contact immunotherapy against multiple VV. VV sometimes regress spontaneously, which may be triggered by accidental contact dermatitis, as shown in our case.

\section{Karger'=}




\section{Case Reports in Dermatology}

\section{Statement of Ethics}

The research was conducted ethically in accordance with the World Medical Association Declaration of Helsinki. The patient has given informed consent, including the use of photographs.

\section{Conflict of Interest Statement}

The authors have no conflicts of interest to declare.

\section{Funding Sources}

The authors have not been funded.

\section{Author Contributions}

All named authors meet the International Committee of Medical Journal Editors (ICMJE) criteria for authorship of the manuscript, take responsibility for the integrity of the work as a whole, and gave final approval of the version to be published.

\section{References}

1 Frosch PJ, John SM. Clinical aspects of irritant contact dermatitis. Contact Dermatitis. Springer; 2011. pp. 305-45.

2 Buckner D, Price NM. Immunotherapy of verrucae vulgares with dinitrochlorobenzene. Br J Dermatol. 1978 Apr;98(4):451-5.

3 Shah KC, Patel RM, Umrigar DD. Dinitrochlorobenzene treatment of verrucae plana. J Dermatol. 1991 Nov;18(11):639-42.

4 Kim KH, Seo KI, Chung JH, Park KC, Eun HC. The effect of diphenylcyclopropenone immunotherapy on molluscum contagiosum. Ann Dermatol. 1993;5(2):79-82. 
Case Reports in Dermatology
Case Rep Dermatol 2021;13:54-57

DOI: $10.1159 / 000511998$

(C) www.karger.com/cde

Egawa et al.: Spontaneous Regression of Warts after Contact Dermatitis
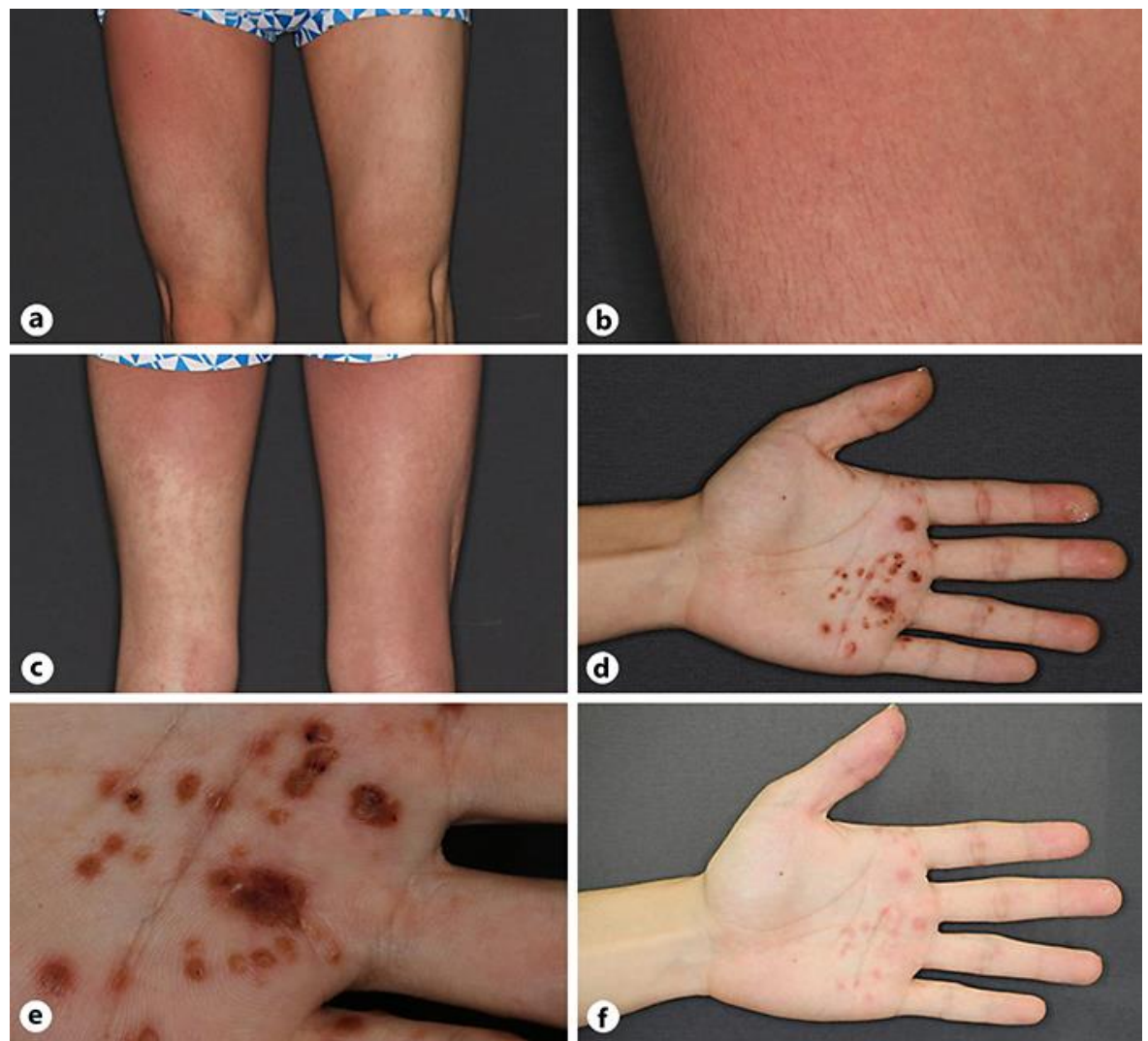

Fig. 1. Clinical manifestations of the patient. a-c Uncircumscribed erythema was found on his right thigh. d, e Multiple warts on the left palm. $\mathbf{f}$ Left palm of the patient 50 days after exposure to alkyl bromide. 